\title{
Combining antihypertensive and antihyperlipidemic agents - optimizing cardiovascular risk factor management
}

\author{
José Zamorano' \\ Jonathan Edwards ${ }^{2}$ \\ 'Hospital Clinico San Carlos, \\ Madrid, Spain; ${ }^{2} U B C$ Scientific \\ Solutions, 5 North Street, \\ Horsham, West Sussex, UK
}

\author{
This article was published in the following Dove Press journal: \\ Integrated Blood Pressure Control \\ I4 November 201 I \\ Number of times this article has been viewed
}

Correspondence: José Zamorano Hospital Clinico San Carlos, Plaza de Cristo Rey, 28040 Madrid, Spain Tel +34 9l 5448940

Fax +34 9I 5448940

Email zamorano@secardiologia.es

\begin{abstract}
Clinical guidelines now recognize the importance of a multifactorial approach to managing cardiovascular (CV) risk. This idea was taken a step further with the concept of the Polypill ${ }^{\mathrm{TM}}$. There are, however, considerable patent, pharmacokinetic, pharmacodynamic, registration, and cost implications that will need to be overcome before the Polypill ${ }^{\mathrm{TM}}$ or other single-pill combinations of CV medications become widely available. However, a medication targeting blood pressure (BP) and lipids provides much of the proposed benefits of the Polypill ${ }^{\mathrm{TM}}$. A single-pill combination of the antihypertensive amlodipine besylate and the lipid-lowering medication atorvastatin calcium (SPAA) is currently available in many parts of the world. This review describes the rationale for this combination therapy and the clinical trials that have demonstrated that these two agents can be combined without the loss of efficacy for either agent or an increase in the incidence of adverse events. The recently completed Cluster Randomized Usual Care vs Caduet Investigation Assessing Long-term-risk (CRUCIAL trial) is discussed in detail. CRUCIAL was a 12-month, international, multicenter, prospective, open-label, parallel design, cluster-randomized trial, which demonstrated that a proactive intervention strategy based on SPAA in addition to usual care (UC) had substantial benefits on estimated CV risk, BP, and lipids over continued UC alone. Adherence with antihypertensive and lipid-lowering therapies outside of the controlled environment of clinical trials is very low ( $-30 \%-40 \%$ at 12 months). Observational studies have demonstrated that improving adherence to lipid-lowering and antihypertensive medications may reduce CV events. One means of improving adherence is the use of single-pill combinations. Real-world observational studies have demonstrated that patients are more adherent to SPAA than co-administered antihypertensive and lipid-lowering therapy, and this improved adherence translated to reduced CV events. Taken together, these findings suggest that SPAA can play an important role in helping physicians improve the management of $\mathrm{CV}$ risk in their patients.
\end{abstract}

Keywords: Polypill ${ }^{\mathrm{TM}}$, multifactorial management, cardiovascular risk, single-pill amlodipine atorvastatin, CRUCIAL study, adherence

\section{Introduction}

Cardiovascular disease (CVD) has a multifactorial nature with CV risk factors rarely occurring in isolation. ${ }^{1-3}$ Indeed, the combination of certain risk factors such as hypertension (HTN) and dyslipidemia (DYS) can act multiplicatively or synergistically to increase the risk of CVD events. ${ }^{4-6}$ This synergistic relationship is recognized by most of the major clinical guidelines used currently to aid the management of patients with symptomatic CVD or at risk of CVD, as they recommend a strategy of treating CVD risk factors simultaneously rather than in isolation. ${ }^{7-10}$ There is an ever-increasing body of evidence describing the advantages of a combined/multifactorial approach to 
reducing CV risk vs the older sequential approach of treating risk factors individually. ${ }^{11-16}$

This multifactorial approach to $\mathrm{CV}$ risk reduction was taken a stage further by Wald and Law in $2003^{13}$ with the suggestion that a combination pill containing a statin, three different antihypertensives (each at half of the standard dose), folic acid, and aspirin could reduce CVD risk by more than $80 \%$. In the 8 years since this paper was published, various pilot studies and Phase II trials of other single-pill combinations of antihypertensives, lipid-lowering medications, and aspirin (eg, the Polycap, which contains low doses of thiazide, atenolol, ramipril, simvastatin, and aspirin) have been completed and published. ${ }^{17-19}$ While the results of some of these studies have been promising, such as the Phase II study of the Polycap, ${ }^{17}$ in other studies the estimated reductions in CVD risk with single-pill combinations of $\mathrm{CV}$ medications have not been as large as those originally estimated by Wald and Law. ${ }^{13,19}$ Furthermore, there are significant patent, potential pharmacokinetic, pharmacodynamic, registration, and cost implications that will need to be overcome before the Polypill ${ }^{\mathrm{TM}} 20$ or other single-pill combinations of $\mathrm{CV}$ medications are approved for use by regulators and become available for general use.

A large proportion of the proposed CV benefits of the Polypill $^{\mathrm{TM}}$ were achieved by targeting HTN and DYS; using the information published in Table 1 of the original Wald and Law paper, ${ }^{13}$ simple calculations demonstrate that the majority $(90 \%)$ of the proposed $88 \%$ benefit of the Polypill ${ }^{\mathrm{TM}}$ on ischemic heart disease and $88 \%$ of the proposed $80 \%$ stroke benefit was due to the use of multiple antihypertensives at low doses and the low dose of a single lipid-lowering agent. ${ }^{13}$ A single-pill combination of the antihypertensive amlodipine besylate and the lipid-lowering agent atorvastatin calcium (single-pill amlodipine/atorvastatin [SPAA]), has been available in the USA since 2004 and in other parts of the world since 2005 .

The remainder of this review will discuss the rationale for combining amlodipine and atorvastatin, and discusses the results of a wide array of preclinical, clinical, and real-world observational studies assessing the efficacy, safety, and utility of the SPAA combination. The Cluster Randomized Usual Care vs Caduet Investigation Assessing Long-term-risk (CRUCIAL trial) will be discussed in detail (Figure 1). This trial is the most recent and longest clinical study of SPAA. ${ }^{21}$ Earlier SPAA studies have been discussed in detail in earlier reviews, ${ }^{22-24}$ so they will not be detailed extensively in this paper. This review will instead focus on the CRUCIAL trial and the recent health economic and outcomes research studies that were not covered in the earlier reviews.

\section{Rationale for the combination of amlodipine and atorvastatin}

One of the driving forces for the development of the Polypill $^{\mathrm{TM}}$ was the poor level of control of CV risk factors, despite the widespread availability of efficacious antihypertensive and lipid-lowering mediations. ${ }^{25-27}$ For example, The European Action on Secondary and Primary Prevention by Intervention to Reduce Events III (EUROASPIRE III) survey carried out in 2006-2007 across 22 countries in Europe ${ }^{26}$ showed that $56 \%$ of patients with symptomatic CVD were not reaching their assigned 2007 European Society of Cardiology (ESC) blood pressure (BP) targets ${ }^{9}$ and over half of patients remained above the recommended ESC lipid targets. The poor level of control of HTN and DYS highlights the need for new strategies to manage these (and other) risk factors thereby reducing the impact of CVD. A single-pill combination of an antihypertensive and lipid-lowering medication may address some of the issues thought to hinder the management of CVD, such as poor adherence to multiple treatments due to high pill burden and the reluctance of physicians to manage more than one CV risk factor simultaneously.

The agents used in a combination medication for the treatment of HTN and DYS should have proven efficacy and excellent tolerability profiles. The antihypertensive component(s) should also be free from drug-drug interactions with other BP-lowering medications due to the frequent need for multiple antihypertensives to achieve BP goals in certain difficult-to-treat populations, such as patients with diabetes. The antihypertensive amlodipine besylate fulfills these criteria in that it has been demonstrated to reduce $\mathrm{CV}$ events in different patient populations ${ }^{28-30}$ and is effective when combined with other classes of antihypertensive. ${ }^{31}$ Amlodipine besylate is a dihydropyridine calcium channel antagonist (calcium channel blocker [CCB]) that primarily inhibits calcium ion influx into cardiac and smooth muscle cells, resulting in peripheral arterial vasodilation and a reduction in BP. ${ }^{32}$ The lipid-lowering agent atorvastatin calcium has also been demonstrated to reduce $\mathrm{CV}$ events in a variety of different patient populations (including those with HTN and $\geq 3$ additional $\mathrm{CV}$ risk factors). ${ }^{12,14,33}$ Atorvastatin is a selective inhibitor of HMG-CoA reductase, the enzyme that converts 3-hydroxy-3-methylglutaryl-coenzyme A to mevalonate, a precursor of cholesterol and lipoproteins, and thereby reduces the formation of lipids. ${ }^{34}$ 


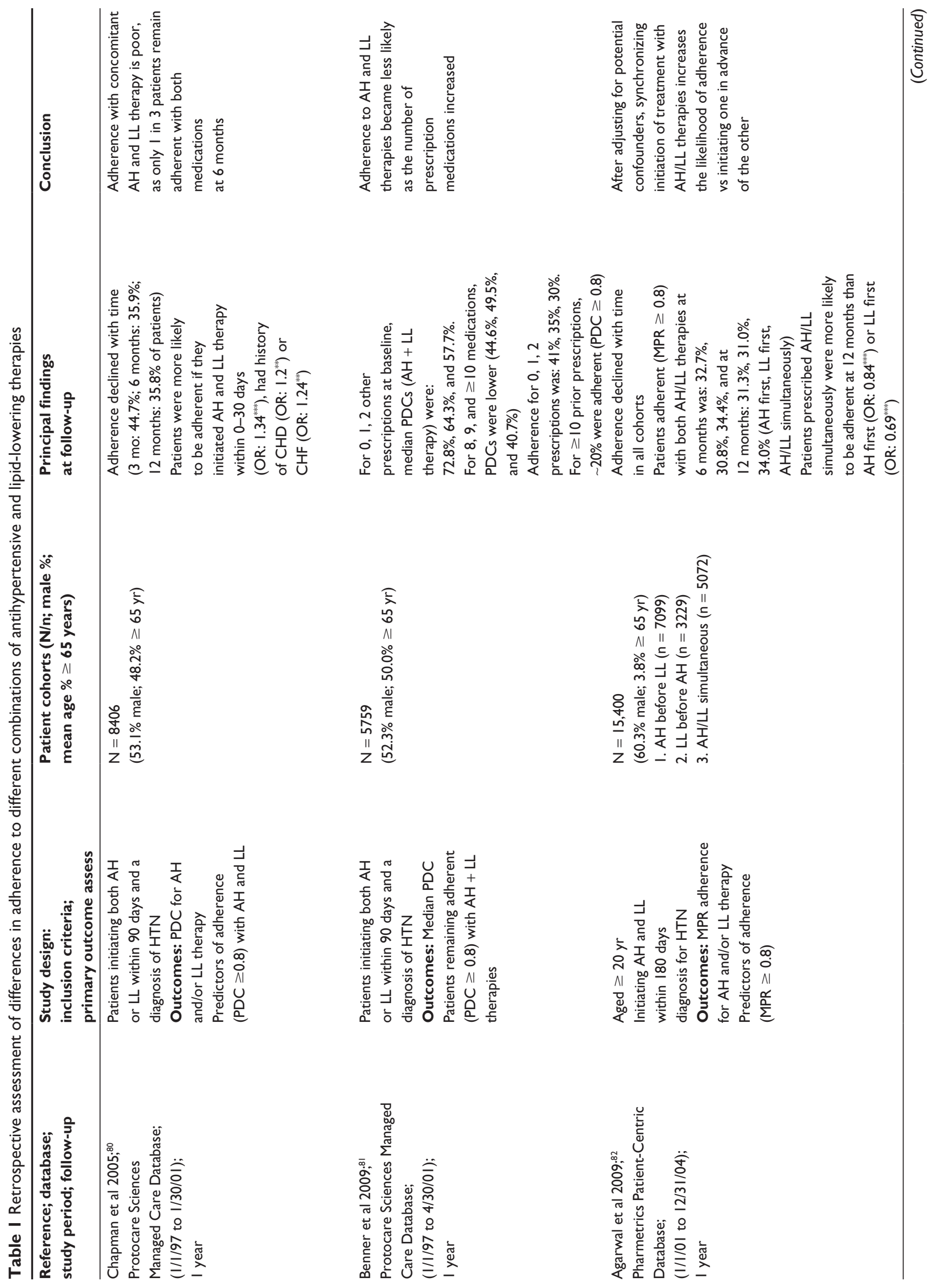




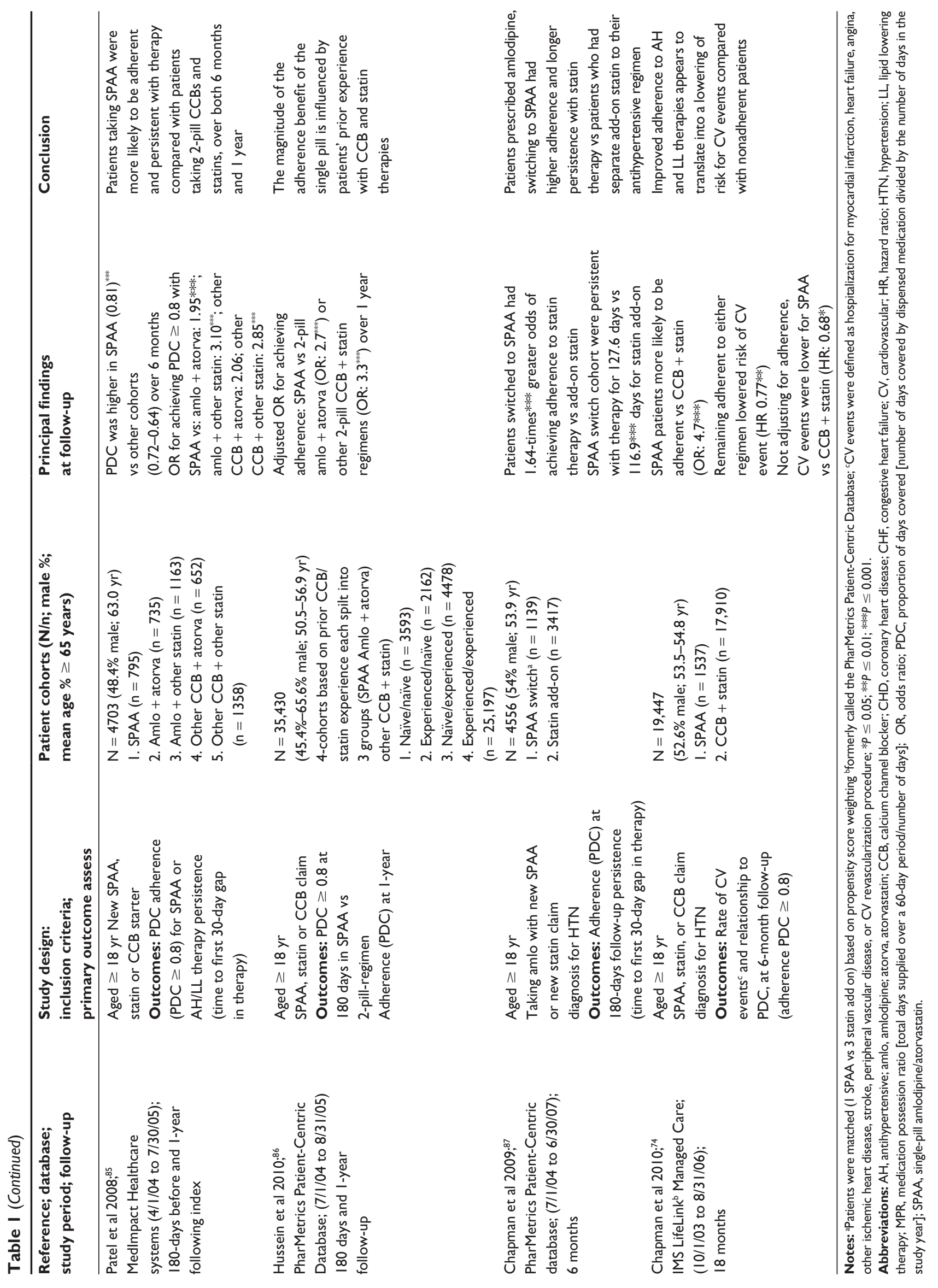


There are a number of important requirements for therapies used in a combination medication, regardless of the condition being treated. Firstly, the medications must have a similar dosing regimen (eg, once- or twice-daily). Secondly, there should be no negative pharmacokinetic or pharmacodynamic interactions between the proposed components (eg, exacerbation of adverse events [AEs] or other drug-drug interactions).
Thirdly, from a patient's perspective, the tablet should be of a reasonable size and the formulations should allow flexible dosing. The following section of this paper will review the evidence for whether or not the combination of amlodipine besylate and atorvastatin calcium fulfills these criteria.

Both amlodipine and atorvastatin can be administered once daily (they are effective for 24 hours) and food causes

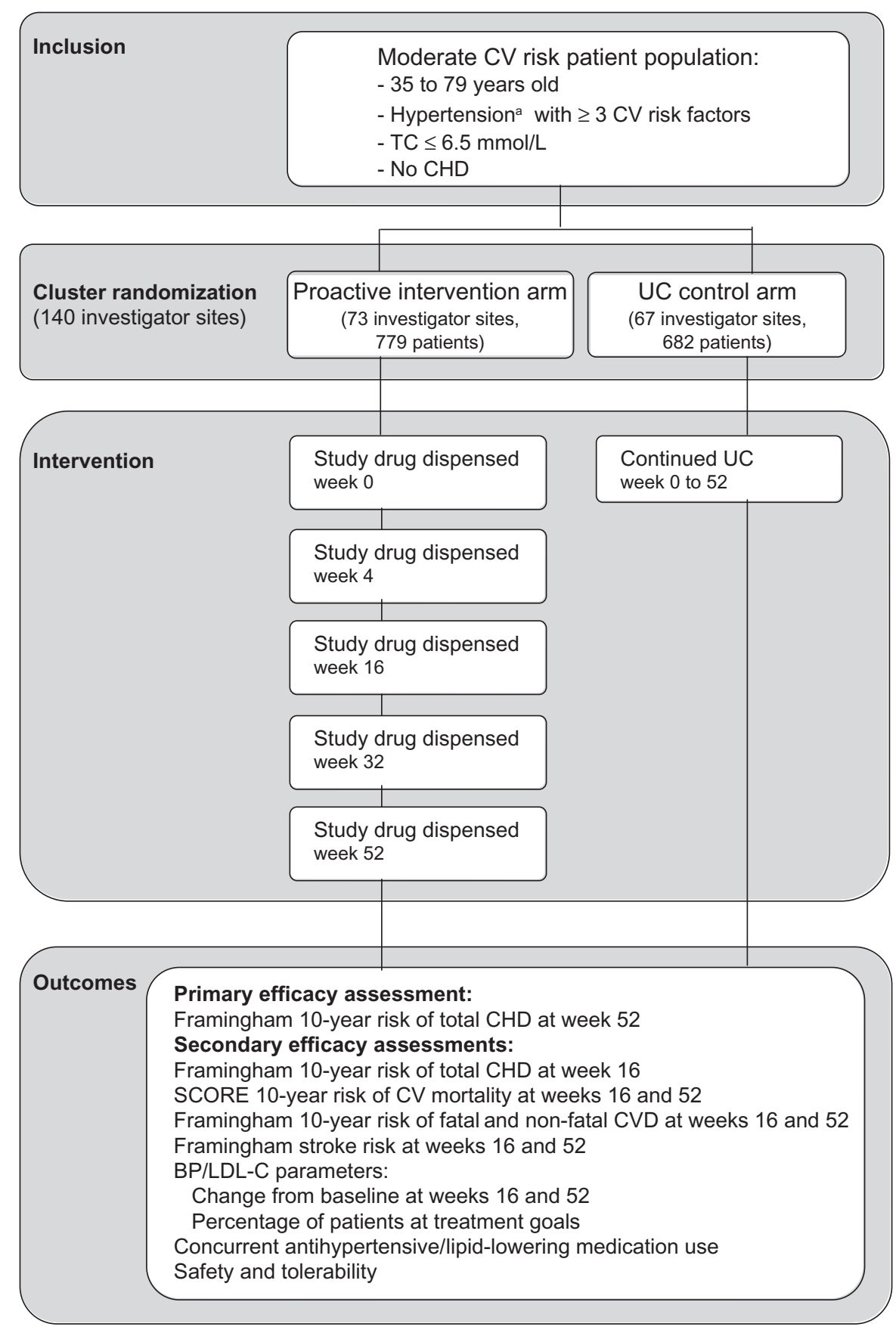

Figure I Design of the CRUCIAL trial.

Notes: aHypertension, untreated: SBP $\geq 160$ and/or DBP $\geq 100 \mathrm{mmHg}$; treated: SBP $\geq 140$ and/or DBP $\geq 90 \mathrm{mmHg}$ or diabetes: SBP $>130$ and/or DBP $>80 \mathrm{mmHg}$. Abbreviations: BP, blood pressure; CHD, congestive heart failure; CV, cardiovascular; CVD, cardiovascular disease; DBP, diastolic blood pressure; LDL-C, low-density lipoprotein cholesterol; SCORE, Systematic COronary Risk Evaluation; SBP, systolic blood pressure; TC, total cholesterol; UC, usual care. 
no clinically meaningful variation in the bioavailability of either agent. ${ }^{35-37}$ The details of the pharmacokinetic properties of amlodipine and atorvastatin as individual agents have been described in detail in earlier reviews ${ }^{22,23,32,34,38}$ and will therefore not be discussed in detail in this paper. Two studies examining the pharmacokinetic properties of co-administered amlodipine and atorvastatin have been published. The first of these studies demonstrated that amlodipine does not affect the pharmacokinetic properties of atorvastatin, and vice versa, under fasting conditions. ${ }^{39}$ The second of these studies demonstrated that the bioavailability of both agents is unchanged when they are administered with food. ${ }^{40}$ Therefore, the pharmacokinetic properties of amlodipine and atorvastatin are well suited and are not a barrier to combining these agents into a single pill.

Two randomized, placebo-controlled clinical trials were undertaken to assess whether amlodipine affects the lipidlowering capacity of atorvastatin, and conversely to evaluate whether atorvastatin affects the BP-lowering efficacy of amlodipine, or if co-administration adversely affects the tolerability of either agent. The first of these studies, the Atorvastatin and Amlodipine in Patients with Elevated Lipids and Hypertension (AVALON) trial, ${ }^{41}$ conducted in 848 patients from the USA and Canada, demonstrated that amlodipine co-administration with atorvastatin did not affect the BP-lowering efficacy of amlodipine. Co-administration of amlodipine $5 \mathrm{mg}$ and atorvastatin $10 \mathrm{mg}$, however, led to a significantly greater effect on low-density lipoprotein cholesterol (LDL-C), total cholesterol (TC), and apolipoprotein B levels at week 8, compared with atorvastatin $10 \mathrm{mg}$ alone. The AVALON study investigators mentioned that these observations were unexpected, and additional studies were needed to explore this further. The second of these two randomized, placebo-controlled clinical trials, Respond, ${ }^{42}$ was a larger trial than AVALON. Respond was conducted across a greater dose range for both amlodipine (placebo; amlodipine $5 \mathrm{mg}$ and $10 \mathrm{mg}$ ) and atorvastatin (placebo; atorvastatin $10 \mathrm{mg}, 20 \mathrm{mg}, 40 \mathrm{mg}$, and $80 \mathrm{mg}$ ) than AVALON. In total, 1660 patients from 15 countries were enrolled. This study demonstrated that atorvastatin did not affect the BP-lowering efficacy of amlodipine and similarly amlodipine did not affect the LDL-C lowering capacity of atorvastatin. There was also no evidence of a higher incidence or exacerbation of AEs in patients receiving both medications vs either agent alone in these two studies. ${ }^{41,42}$ Therefore, these studies demonstrated that there were no pharmacodynamic or pharmacokinetic barriers to combining amlodipine and atorvastatin into a single pill.
Indeed, there is some evidence that there might be some pharmacodynamic benefits associated with combining these agents. A wide variety of both preclinical and clinical studies has assessed the separate and combined effects of amlodipine and atorvastatin on cell systems, arterial wall compliance, and CV endpoints. ${ }^{43-45}$ Studies conducted using human umbilical vein endothelial cells to evaluate the effects of amlodipine and atorvastatin alone and in combination on nitric oxide (NO) release demonstrated that co-administered amlodipine and atorvastatin had a synergistic effect on increasing NO concentrations. This in turn reduced nitroxidative stress. Furthermore, co-administered amlodipine and atorvastatin partially restored NO levels following LDL-C-induced endothelial dysfunction. ${ }^{44}$ An AVALON substudy demonstrated a 19\% improvement in small artery compliance (C2) with co-administered amlodipine $5 \mathrm{mg}$ and atorvastatin $10 \mathrm{mg}$ in patients with HTN and DYS from baseline to week 8 , which was significantly greater than with either amlodipine $5 \mathrm{mg}$ or atorvastatin alone or placebo. ${ }^{45}$ Moreover, a potential beneficial interaction between atorvastatin and amlodipine was suggested by the results of a pre-specified $2 \times 2$ factorial analysis of data from the Anglo-Scandinavian Cardiac Outcomes Trial (ASCOT). Compared with placebo, the risk reduction of non-fatal myocardial infarction (MI) and fatal coronary heart disease (CHD) was greater in patients receiving an atorvastatin- plus amlodipine-based regimen than in those receiving an atorvastatin- plus atenolol-based regimen. ${ }^{43}$

SPAA tablets are available in a range of amlodipine/ atorvastatin doses from $2.5 / 10 \mathrm{mg}$ to $10 / 80 \mathrm{mg}$. However, the doses approved vary from country to country with just $5 / 10 \mathrm{mg}$ and 10/10 mg available in some parts of Europe. SPAA pills are not particularly large and there have been no reports of the size of the SPAA being an issue for patients. Indeed, a small pilot study indicated that patients were satisfied with SPAA treatment in relation to their previous treatment of HTN and DYS. ${ }^{46}$ This therefore suggests that the pill size is not a barrier to use and the dose strengths available enable flexible dosing.

\section{Safety considerations and contraindications}

Amlodipine and atorvastatin have been used in routine clinical practice both alone and in combination for many years. Initial safety concerns surrounding the use of CCBs, which were based on the results of observational studies were not substantiated in a series of large randomized trials, which provided evidence on both the efficacy and safety of amlodipine 
in a broad range of patients. ${ }^{11,12,28,47}$ Furthermore, clinical trials and meta-analyses have demonstrated that atorvastatin is an effective and well-tolerated medication. ${ }^{12,14,48,49}$ A retrospective analysis of 49 clinical trials of atorvastatin demonstrated that the overall incidence of treatment-associated AEs in patients receiving atorvastatin was similar to that in patients receiving placebo. ${ }^{49}$ Furthermore, many of the side effects associated with statins such as atorvastatin, tend to be dose related and often resolve when treatment is stopped or if the dose is reduced. ${ }^{22}$ Nevertheless, the safety considerations for, and contraindications of, both amlodipine and atorvastatin need to be considered before prescribing these medications as SPAA.

In terms of contraindications, SPAA should not be used in patients with a known sensitivity to either amlodipine or atorvastatin, or in women who are, or may become, pregnant or women who are breast feeding. ${ }^{37}$ SPAA is also contraindicated in patients with active liver disease or unexplained persistent elevations in hepatic transaminases. Rare cases of rhabdomyolysis have been reported in patients treated with atorvastatin and other statins. Therefore, patients should be advised to report promptly muscle pain, tenderness, or weakness to their physician. Patients with a history of renal failure, which can exacerbate the risk of muscle damage, should be closely monitored for rhabdomyolysis. ${ }^{37}$ Other factors that may predispose patients to myopathy are advancing age ( $\geq 65$ years) and hypothyroidism. Treatment with SPAA should be temporarily withheld or discontinued if a patient develops myopathy or rhabdomyolysis. Furthermore, dosing instructions should be followed carefully when SPAA is co-administered with fibric acid derivatives, niacin, cyclosporine, clarithromycin, itraconazole, or HIV protease inhibitors - medications that can increase the risk of myopathy or rhabdomyolysis. Statins have also been associated with abnormalities in liver function. ${ }^{37}$ Therefore, it is recommended that liver function tests are undertaken before and 12 weeks after initiating therapy with, or increasing the atorvastatin component of, SPAA. If persistent elevations in liver enzymes occur, reduction in the dose of SPAA or withdrawal of SPAA is recommended. ${ }^{37}$

Caution is required when treating certain patient populations with SPAA. For example, elderly patients should initiate treatment at the low end of the dose range for amlodipine, and patients with hepatic impairment should have their dose titrated slowly. ${ }^{36}$ Furthermore, a potential worsening of angina and acute MI (particularly in patients with severe obstructive coronary artery disease) can develop on initiating amlodipine or increasing the dose of this medication. ${ }^{37}$ Caution is also advised when prescribing high doses of atorvastatin in patients with a recent stroke. ${ }^{35,37}$ This advisory is based on a post hoc analysis of the Stroke Prevention by Aggressive Reduction in Cholesterol Levels (SPARCL) study. ${ }^{50}$ Patients in this study had no history of CHD but had a stroke or transient ischemic attack within the preceding 6 months. A higher incidence of hemorrhagic stroke was seen in the atorvastatin $80-\mathrm{mg}$ group compared with placebo (2.3\% vs $1.4 \%)$. Some baseline characteristics, including hemorrhagic and lacunar stroke on study entry, were associated with a higher incidence of hemorrhagic stroke in the atorvastatin group.

See the SPAA package insert for full details on the contraindications, precautions, and dosing requirements for SPAA. ${ }^{37}$

\section{Treatment objectives: efficacy studies} Single-pill amlodipine/atorvastatin studies The AVALON ${ }^{41}$ and Respond ${ }^{42}$ studies outlined above both used co-administered amlodipine and atorvastatin rather than SPAA. A variety of both open-label and randomized controlled studies has now been conducted to evaluate the efficacy and tolerability of SPAA. The first of these was the GEMINI trial, which was a 14-week, open-label trial conducted in 1220 patients from the USA, which demonstrated that SPAA was well tolerated and could help patients with HTN and DYS achieve their BP and LDL-C goals. ${ }^{51}$ The subsequent GEMINI-Australia, Asia, Latin America, Africa/ Middle East (AALA) study, which was a very similar study design, confirmed the findings of GEMINI among 1649 patients residing across Asia Pacific, the Middle East, Africa, and Latin America. ${ }^{52}$ The findings of these two studies were confirmed in the JEWEL study program, with JEWEL 1 conducted among 1138 patients from the UK and Canada and JEWEL 2 conducted in 1107 patients from Europe. ${ }^{53} \mathrm{~A}$ further study on the use of SPAA in the USA, the Clinical Utility of Caduet in Simultaneously Achieving Blood Pressure and Lipid End Points (CAPABLE ${ }^{54}$ ), was conducted in 499 African American patients. CAPABLE examined the efficacy and safety of SPAA in a population that is rarely studied and has a high prevalence of HTN and mortality rates from CVD compared with other ethnic groups in the USA. In the CAPABLE trial, dual goal attainment was improved after 20 weeks of SPAA (48.3\% patients achieved their BP and LDL-C goals vs $0.8 \%$ at baseline). 
Taken as a whole, these studies demonstrate the clinical utility and good tolerability profile of SPAA across patients with HTN and DYS alone as well as those with additional $\mathrm{CV}$ risk factors, diabetes/metabolic syndrome, ${ }^{55}$ and symptomatic CVD. ${ }^{51,52,54,56}$ The data from GEMINI, GEMINI-AALA, JEWEL 1/2, and CAPABLE have been pooled and used to compare changes in BP when SPAA was used as first-line vs add-on antihypertensive treatment, and to investigate changes in LDL-C when SPAA was used as first-line vs replacement lipid-lowering treatment. Similar BP reductions were observed when SPAA was used as firstline or add-on antihypertensive treatment. Although LDL-C reductions were greater when SPAA was used as first-line vs replacement lipid-lowering treatment, both groups were observed to have clinically beneficial lowering of LDL-C. ${ }^{57}$ Data from this pooled analysis were also used to compare BP lowering and LDL-C reduction after treatment with SPAA in patients aged $\geq 75$ years and $<75$ years, ${ }^{58}$ and in men and women aged $\geq 65$ years and $<65$ years with HTN and DYS. ${ }^{59}$ The first of these analyses demonstrated that SPAA was similarly effective at lowering BP and LDL-C in patients aged $\geq 75$ years and $<75$ years, ${ }^{58}$ The second analysis indicated that systolic BP reductions were similar but diastolic BP reductions tended to be greater in the older ( $\geq 65$ years) vs the younger $(<65$ years) group in both men and women. In both age groups women tended to have higher baseline LDL-C and greater LDL-C reduction than men. ${ }^{59}$

In addition to the non-comparative open-label 'realworld' GEMINI, GEMINI-AALA, JEWEL, and CAPABLE studies, two randomized, double-blind, placebo-controlled trials have also been conducted to evaluate the efficacy of SPAA. The first of these studies, CUSP (The Caduet ${ }^{\circledR}$ in an Untreated Subject Population trial), ${ }^{60}$ compared SPAA plus therapeutic lifestyle changes (TLC) with placebo plus TLC in 130 US patients with HTN and DYS but without CHD, who were not being treated with either antihypertensives or lipid-lowering agents. Significantly more patients receiving SPAA and TLC reached both BP and LDL-C goals at study end compared with TLC and placebo (55.6\% vs $5.0 \%$ ). The second of these studies, the TOGETHER trial, evaluated whether targeting multiple $\mathrm{CV}$ risk factors with SPAA (5/20-10/20 mg) and TLC resulted in greater BP/lipid control and additional reduction in CVD risk in comparison with amlodipine (5-10 mg) plus TLC in patients with HTN and additional CV risk factors (but not CVD or diabetes). ${ }^{61}$ At the end of this 6-week study, significantly more patients receiving SPAA reached both BP and LDL-C goals compared with patients receiving only amlodipine (67.8\% vs 9.6 ; odds ratio $[\mathrm{OR}]: 19.0 ; 95 \%$ confidence interval [CI]: 9.1-39.6; $P<0.001){ }^{61}$

\section{The CRUCIAL study}

The CRUCIAL study is the only long-term randomized comparative trial of SPAA. ${ }^{21}$ CRUCIAL was a 12 -month, international, multicenter, prospective, open-label, parallel design, cluster-randomized trial conducted in 19 countries in four geographical regions, including Asia, the Middle East, Europe, and Latin America, between March 2007 and October 2009 (Figure 1). CRUCIAL was the first study designed to investigate whether a proactive multifactorial risk factor intervention strategy using SPAA (based on SPAA [5/10,10/10 mg] plus continuing usual care [UC]) resulted in greater reduction in calculated Framingham 10-year CHD risk compared with UC alone.

A total of 1461 patients aged 35-79 years with HTN (untreated or treated), TC $\leq 6.5 \mathrm{mmol} / \mathrm{L}$ (untreated), and three or more additional $\mathrm{CV}$ risk factors, with or without diabetes but without CHD, were enrolled and received treatment. Investigators randomized to the proactive intervention strategy arm initiated their patients on SPAA at 5/10 mg to $10 / 10 \mathrm{mg}$ and, if approved in the participating country, this was increased to $5 / 20 \mathrm{mg}$ and $10 / 20 \mathrm{mg}$. In the UC arm, the investigator had the full choice of any locally approved (and not contraindicated) antihypertensive and/or lipid-lowering drugs based solely on the investigators' clinical judgment, including, but not limited to, amlodipine, atorvastatin, or SPAA.

The primary efficacy endpoint was the calculated 10-year risk of developing CHD at 52 weeks using a Framingham CHD model. ${ }^{62}$ Secondary efficacy endpoints included postbaseline changes in BP and lipids, BP and LDL-C goal attainment, and additional measures of CHD or CVD risk such as the European SCORE 10-year risk of CV mortality, ${ }^{63}$ the 10-year Framingham risk for fatal and non-fatal CVD, ${ }^{64}$ and the Framingham stroke risk. ${ }^{65}$

The proactive intervention strategies with SPAA and UC treatment arms were well matched for gender $(53.4 \%$ vs $50.5 \%$ male), age ( 60.0 vs 60.3 years), and race (white $45.8 \%$ vs $47.6 \%$; Asian $34.9 \%$ vs $36.2 \%$ ). At baseline, LDL-C levels were similar (119.4 vs $118.0 \mathrm{mg} / \mathrm{dL})$ in the two treatment arms. BP, however, was higher at baseline in the proactive intervention strategy than in the UC arm (systolic BP 150.3 vs $144.3 \mathrm{mmHg}$ and diastolic BP 89.7 vs $86.5 \mathrm{mmHg}$, respectively). This led to a higher calculated baseline absolute Framingham 10-year CHD risk in the proactive intervention strategy compared with the UC arm (20.0\% vs $18.1 \%)$. 
The reasons for the difference in BP between the treatment arms at baseline are uncertain. However, it is possible that they are related to the cluster randomization used in this study in which the investigators rather than the patients were randomized. The following precautions were taken to balance the treatment arms for potentially confounding factors. Firstly, patients were enrolled into the study before the investigators were randomized to avoid patient selection bias. Secondly, study investigators were randomized in a 1:1 ratio within each country. Post-baseline evaluations of CHD, CVD or stroke risk, and BP were adjusted to account for these differences in BP and Framingham CHD risk at baseline.

The majority of patients in the proactive intervention strategy arm were taking antihypertensives in addition to SPAA ( $85 \%$ at week 16 and $86 \%$ at week 52), but few patients were taking additional lipid-lowering agents (5.9\% at week 16 and $6.1 \%$ at week 52; Figure 2). The mean dose of SPAA at study endpoint was amlodipine $6.5 \mathrm{mg} /$ atorvastatin $11.0 \mathrm{mg}$. In the UC arm nearly all patients received antihypertensives (97\% at week 16 and $97 \%$ at week 52 ) with a mean (SD) of $2.5(1.3)$ and 2.6 (1.4) antihypertensive medications per patient at weeks 16 and 52. Less than one third of patients in the UC arm received lipid-lowering therapy (31\% at week 16 and $32 \%$ at week 52 ). This was despite the benefits of lipid-lowering therapy previously observed in this patient population in ASCOT-LLA. ${ }^{12}$

At study endpoint (week 52), mean absolute Framingham CHD risk was $12.5 \%$ in the proactive intervention strategy arm and $16.3 \%$ in the UC arm $(P<0.001)$, which represented a relative risk reduction of $-33.0 \%$ vs $-4.0 \%$. Other measures of CVD and stroke risk were similarly reduced to a much greater extent in the proactive intervention strategy vs the UC arm (Figure 3). It should be recognized that estimated CHD, CVD, or stroke risk are all surrogates for hard $\mathrm{CV}$ endpoints that have not been validated for assessing the impact of BP or lipid-lowering medications on $\mathrm{CV}$ endpoints. ${ }^{21}$ However, both amlodipine and atorvastatin have been demonstrated to reduce hard $\mathrm{CV}$ endpoints in a clinical trial with similar patient inclusion and exclusion requirements to CRUCIAL. ${ }^{12,29,43}$

The mean absolute BP reductions from baseline at week 52 in the proactive intervention arm and the UC arm were $-19.8 \mathrm{vs}-10.0 \mathrm{mmHg}$ (systolic) and $-10.5 \mathrm{vs}-5.3 \mathrm{mmHg}$ (diastolic), respectively (Figure 4). The mean relative LDL-C reduction from baseline at week 52 in the proactive intervention arm was $25.6 \%$, whereas LDL-C increased by $2.7 \%$ in the UC arm (Figure 4). These substantial reductions in both $\mathrm{BP}$ and LDL-C in the proactive intervention arm using SPAA were driving the fall in estimated CHD, CVD, and stroke risk (Figure 3).

Attainment of Joint National Committee on the prevention, detection, evaluation, and treatment of high blood pressure 7: (JNC 7) BP goals ${ }^{8}$ was slightly higher in the proactive intervention vs the $\mathrm{UC}$ arm at week 16 (49\% vs 46\%; OR: 1.08 ; 95\% CI: $0.79-1.48 ; P=0.618$ )

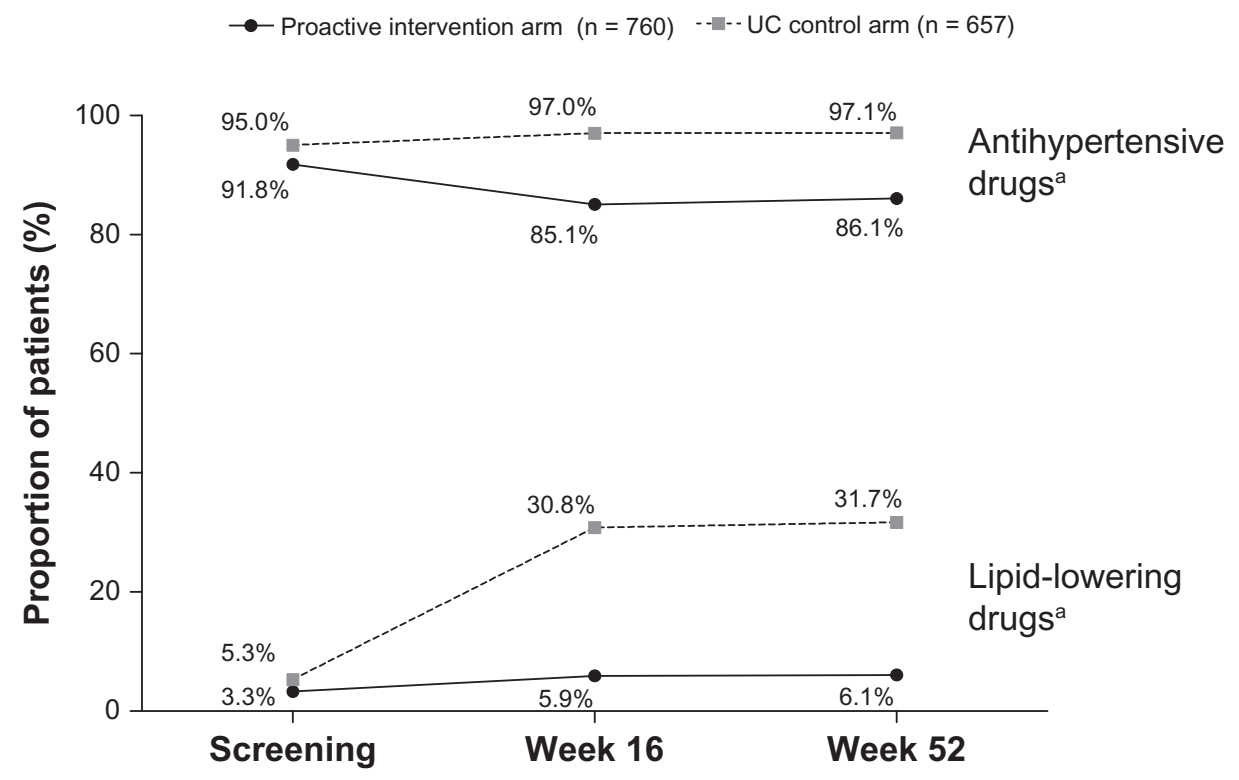

Figure 2 Concurrent antihypertensive and lipid-lowering medication use at screening and at weeks I6 and 52 in the CRUCIAL trial.

Notes: aln the proactive intervention arm these are antihypertensive and lipid-lowering medications in addition to SPAA; in the UC arm these are the total number of antihypertensive and lipid-lowering medications.

Abbreviations: SPAA, single-pill amlodipine/atorvastatin; UC, usual care. 


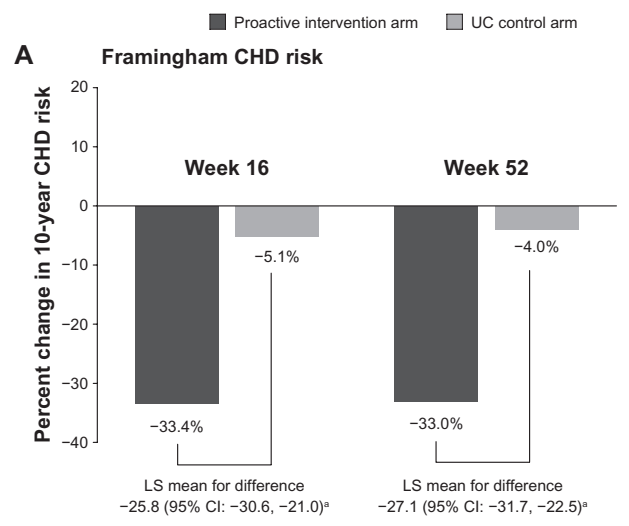

B European SCORE fatal CV risk

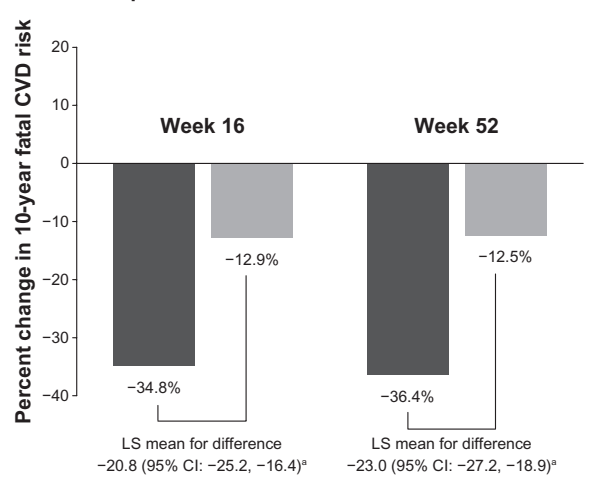

C Framingham fatal/non-fatal CVD risk

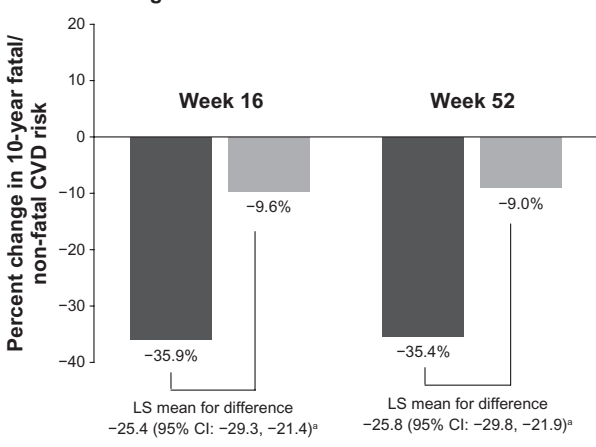

D Framingham stroke risk

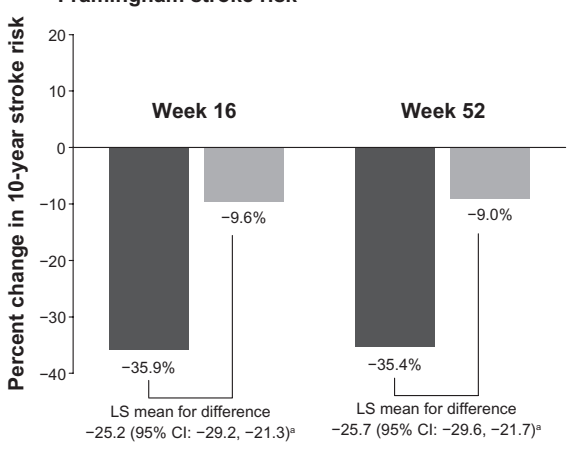

Figure 3 Percentage change in calculated 10-year (A) Framingham CHD risk, (B) European SCORE fatal CV risk, (C) Framingham fatal and non-fatal CVD risk, (D) Framingham stroke risk from baseline to week 16 and 52, by treatment arm in the CRUCIAL trial.

Note: a $P<0.001$.

Abbreviations: CHD, coronary heart disease; $\mathrm{Cl}$, confidence interval; CRUCIAL, Cluster Randomized Usual Care vs Caduet Investigation Assessing Long-term-risk; CV, cardiovascular; CVD, cardiovascular disease; LS, least squares; SCORE, Systematic COronary Risk Evaluation model; UC, usual care.

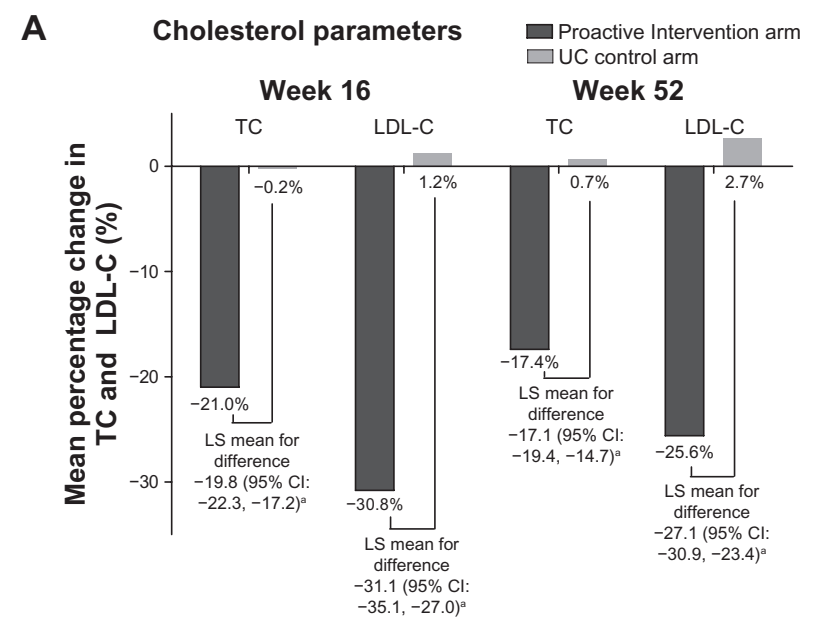

B

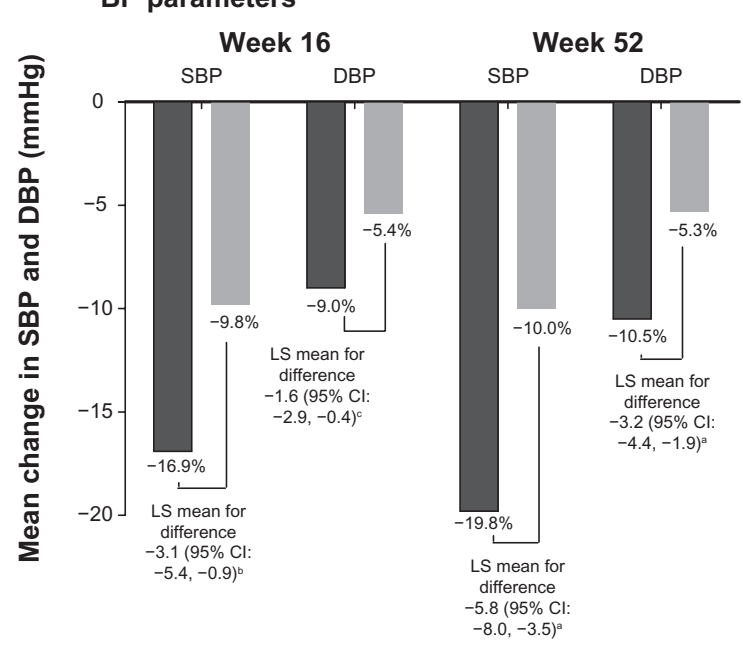

Figure 4 Mean change from baseline in (A) cholesterol and (B) BP parameters at weeks 16 and 52 in the CRUCIAL trial.

Notes: ${ }^{a} P<0.001$; ${ }^{\text {b }} P<0.01$; ${ }^{\mathrm{c} P}<0.05$.

Abbreviations: $\mathrm{BP}$, blood pressure; $\mathrm{Cl}$, confidence interval; $\mathrm{CRUCIAL}$, Cluster Randomized Usual Care vs Caduet Investigation Assessing Long-term-risk; DBP, diastolic blood pressure; LDL-C, low-density lipoprotein cholesterol; LS, least squares; SBP, systolic blood pressure; TC, total cholesterol; UC, usual care.

and this increased to $58 \%$ vs $48 \%$ (OR: $1.59 ; 95 \%$ CI: $1.15-2.2 ; P<0.001)$ at week 52. Attainment of the National Cholesterol Education Program (NCEP) expert panel on detection, evaluation, and treatment of high blood cholesterol in adults (Adult Treatment Panel III) (NCEP ATP III) ${ }^{7}$ LDL-C goals was markedly higher in the proactive intervention vs the UC arm at both week 16 (88\% vs 53\%; OR: 7.1; 95\% CI: 5.17-9.73; $P<0.001$ ) and week 52 ( $83 \%$ vs $53 \%$; OR: 4.39 ; $95 \%$ CI: 3.31-5.82; $P<0.001)$. Dual BP/LDL-C goal attainment was also achieved in a significantly higher proportion of patients in the proactive intervention using SPAA vs the UC arm at both week 16 (43\% vs $26 \%$; OR: 2.1 ; $95 \%$ CI: $1.56-2.90$; $P<0.001)$ and week 52 . (50\% vs $27 \%$; OR: $2.83 ; 95 \%$ CI: 2.11-3.90; $P<0.001)$. 
The evaluation of AEs in CRUCIAL was complicated by the fact that only patients in the proactive intervention arm received study medication (SPAA). Patients in the UC arm continued their existing antihypertensive and lipidlowering medications, which were presumably well tolerated in that they had not been discontinued due to AEs or other safety concerns before entering the study. Most AEs in both treatment arms were mild to moderate in intensity. However, more patients discontinued their treatment due to AEs in the proactive intervention $(6.7 \%)$ than in the UC arm $(0.6 \%)$. The most commonly reported AEs in the proactive intervention arm were peripheral edema (6.8\%), headache (3.0\%), and nasopharyngitis $(2.8 \%)$ in comparison with headache $(2.2 \%)$, bronchitis $(2.2 \%)$, and upper respiratory tract infection $(2.1 \%)$ in the UC arm. There were no treatment-related deaths in either treatment group. The incidence of AEs in the proactive intervention arm was similar to that previously observed for SPAA $^{52}$ and co-administered amlodipine and atorvastatin. ${ }^{42}$

A number of sub-analyses of the CRUCIAL study have been undertaken, with more planned in the future. In the first of these sub-analyses, the efficacy and tolerability of the proactive intervention strategy vs UC was assessed in patients with $(n=600)$ and without $(n=817)$ diabetes.$^{66}$ The reductions in Framingham CHD risk and BP in patients in the proactive intervention arm vs UC were similar in those with and without diabetes. The SPAA-based treatment in the proactive intervention arm was well tolerated in patient groups, in line with previous studies. ${ }^{51,52} \mathrm{~A}$ similar evaluation assessing the proactive intervention arm resulted in a greater reduction in calculated Framingham 10-year CHD risk, BP, or LDL-C compared with continuing UC in younger ( $<65$ years) and older ( $\geq 65$ years) patients. This sub-analysis demonstrated that reductions in Framingham 10 -year CHD risk, systolic BP, and lipids in the patients in the proactive intervention arm vs UC were similar in both older and younger patients, and SPAA-based treatment was well tolerated. ${ }^{67}$ However, in patients treated with the proactive intervention vs $\mathrm{UC}$, the reductions in diastolic $\mathrm{BP}$ were higher for younger than older patients.

Additional sub-analyses evaluating the efficacy and safety of the proactive intervention in comparison with UC in Pacific-Asian vs non-Pacific-Asian patients have been undertaken ${ }^{68}$ A separate evaluation of the Pacific-Asian patients from the CRUCIAL population has compared baseline and endpoint $\mathrm{CV}$ risk estimations, made using the Japanese NIPPON DATA80 ${ }^{69}$ risk assessment chart (which is based on Japanese longitudinal CV data), with the Framingham and SCORE risk assessments. ${ }^{70} \mathrm{~A}$ further analysis evaluating efficacy and safety of the proactive intervention in comparison with UC in Latin American vs non-Latin American patients is also underway.

In conclusion, the CRUCIAL study demonstrated that a proactive intervention strategy based on SPAA had substantial benefits on estimated CHD/CVD risk, BP, and lipids over continued UC in patients with HTN, TC $\leq 6.5 \mathrm{mmol} / \mathrm{L}$ (untreated), and three or more additional CV risk factors, with or without diabetes but without CHD.

\section{Health outcome and pharmacoeconomic studies}

The results of the CRUCIAL trial clearly demonstrate the benefits of SPAA-based treatment vs UC within the controlled environment of a clinical trial. A broad range of observational studies has evaluated the effectiveness of SPAA in the real-world setting and the potential benefits of the use of SPAA in comparison with co-administered amlodipine and atorvastatin. Furthermore, a pharmacoeconomic evaluation using transition probabilities and costs from the ASCOT study indicated that the combination of amlodipine-based therapy and atorvastatin was cost-effective in patients with similar characteristics to those enrolled in CRUCIAL (HTN and three or more additional risk factors but no CHD). ${ }^{71}$ However, additional studies evaluating the costs of SPAA vs potential cost savings related to the benefits of this medication on $\mathrm{CV}$ endpoints in the real-world setting are required to confirm these findings.

One of the key reasons for combining two or more agents into a single pill is that it reduces pill burden and thus simplifies a patient's treatment regimen, which can in turn improve patient adherence..$^{72}$ This has important implications because improvement in patient adherence may increase therapeutic goal attainment, and in the long term improve health outcomes and reduce $\mathrm{CV}$ events. ${ }^{73,74}$ Conversely, poor adherence to antihypertensive and lipid-lowering therapies can substantially reduce the effectiveness of these medications. ${ }^{75-79}$ For example, hypertensive patients taking antihypertensive and statin therapy at real-world adherence levels can be expected to receive only approximately $50 \%$ of the potential benefit demonstrated in clinical trials. ${ }^{78}$

Given the importance of adherence to medications that lower $\mathrm{CV}$ risk and the potential adherence benefits of single-pill combination medications over co-administered therapies, ${ }^{72}$ several studies have assessed predictors of adherence and nonadherence to antihypertensive and 
lipid-lowering medications (Table 1). These studies have provided information on the factors that may play a role in driving the improved adherence to single-pill combination medications. The first of these studies evaluated adherence to antihypertensive and lipid-lowering medications in 8406 patients with HTN newly initiated on these medications. ${ }^{80}$ Adherence to antihypertensive and lipid-lowering medications was very low, just $36 \%$ of patients remaining adherent to both classes of medication at 12 months (Table 1). This study also suggested that increasing pill burden could decrease adherence ${ }^{80}$ and that patients were more likely to be adherent to their antihypertensive and lipid-lowering therapy if they initiated antihypertensive and lipid-lowering medications together, or had symptomatic CVD (Table 1). ${ }^{80}$ The relationship between pill burden and adherence was assessed in more detail in a later study, which confirmed that adherence decreases as the number of medications a patient was taking increased (Table 1). ${ }^{81}$ The effect of the timing of antihypertensive and lipid-lowering medication initiation was studied in more detail in a subsequent study, which confirmed that synchronized initiation of these two classes of therapy improves adherence compared with initiating them separately (Table 1). ${ }^{82}$

All of the above retrospective database studies demonstrated that overall adherence to antihypertensive and lipid-lowering medications is low, falling to just 30\%- 40\% at 12 months after initiating therapy (Table 1). ${ }^{80,82}$ This therefore suggests that interventions to maintain and improve adherence to these medications over time are required. The effectiveness of interventions designed to improve adherence has been evaluated, and was identified in two systematic literature reviews. ${ }^{83,84}$ The first of these reviews identified a range of interventions that had successfully improved adherence to antihypertensive or lipid-lowering medications, such as fixed-dose combinations, unit-dose packaging, educational telephone calls, case management by pharmacists or nurses, and mailed refill reminders. ${ }^{83}$ The second evaluation extended and updated the first review, by additionally comparing the effectiveness and costs of interventions to improve adherence to antihypertensive and lipid-lowering therapies. ${ }^{84}$ Effectiveness was measured as relative improvement (RI) in adherence, which was defined as the ratio of adherence in the intervention group to the control group. The control group comprised patients taking antihypertensive and lipid-lowering therapies alone without any intervention program. Costs were calculated based on those reported in the analysis, if available, or estimated based on resource use described in each publication and using standard costs derived from the literature. Across five eligible studies, RI in adherence ranged from 1.11 for mailed refill reminders to 4.65 for case management by a community pharmacist. The costs of interventions over 6 months ranged from US\$10 per patient for monthly mailed reminders to US\$142 per patient for a combination of increased pharmacy care, and the use of patient diaries and educational material. In general, the more costly and time-consuming interventions were the most effective. However, across most healthcare systems it is unlikely that there will be sufficient resources available to provide intensive case management for all patients nonadherent to their antihypertensive and lipid-lowering medications.

\section{Adherence benefits of single-pill amlodipine/atorvastatin}

The use of fixed-dose combination medications has been shown to be an effective approach to improving patient adherence to therapies across a diverse range of disease areas, such as HTN, tuberculosis, HIV, and diabetes. ${ }^{72}$ The Caduet Adherence Research Program and Education (CARPE) retrospective cohort studies were designed to evaluate potential adherence benefits of SPAA vs co-administered antihypertensive and lipid-lowering therapy in real-world settings (Table 1).

The first of these studies, CARPE-Patient Benefits Management (CARPE-PBM), was a retrospective database study of pharmacy claims data that identified patients who were newly initiated on SPAA, or a CCB or statin (either simultaneously or within 30 days of each other). At 6-month follow-up, and after adjustments for differences between the cohorts, patients prescribed SPAA were significantly more likely to achieve adherence vs two-pill regimen amlodipine plus atorvastatin (OR: 1.95; 95\% CI: 1.80-2.13). ${ }^{85}$

The CARPE-M study provided further insight into the potential adherence benefits of SPAA, by investigating the impact of prior CCB and statin use on adherence to SPAA. Although this study supported the finding of CARPE-PBM (higher adherence in patients receiving SPAA vs those receiving a two-pill regimen), CARPE-M also suggested that patients with prior experience of either CCB or statin use (but not both) were more likely to adhere to their SPAA treatment compared with treatment-naïve patients or those who had previous experience with both of these therapies (Table 1). ${ }^{86}$

A similar study was undertaken to see if adherence to antihypertensive therapy can be used to promote adherence 
to statin therapy ${ }^{87}$ This study question was addressed by evaluating adherence to statin therapy in hypertensive patients taking amlodipine switching to SPAA in comparison with patients adding a separate statin to their amlodipine regimen. At 6-month follow-up, patients who switched to SPAA were more likely to be adherent and to persist with their therapy than those adding a statin (Table 1).

The last study in this series, CARPE-M events examined whether improving adherence to SPAA was associated with a lower risk of $\mathrm{CV}$ events in patients with $\mathrm{HTN}$ but no prior history of $\mathrm{CV}$ events. ${ }^{74}$ The primary measure in this study was the rate of $\mathrm{CV}$ events from 6 to 18 months following the initiation of antihypertensive therapy. The $\mathrm{CV}$ event rate was compared in three ways: (1) all adherent vs nonadherent patients; (2) SPAA vs two-pill therapy (CCB/statin patients regardless of adherence level); and (3) adherent SPAA, adherent two-pill, and nonadherent SPAA patients vs nonadherent two-pill patients. After 6 months of treatment, $56.5 \%$ of the 1537 SPAA patients were adherent vs $21.4 \%$ of the 17,910 two-pill therapy patients (OR: $4.7 ; P<0.001$ ). For comparison (1), of all adherent vs nonadherent patients, remaining adherent to therapy was associated with significantly lower risk of CV event (hazard ratio [HR]: $0.77 ; P=0.003$ ). SPAA was also associated with fewer $\mathrm{CV}$ events when differences in adherence were not factored in (HR: $0.68 ; P=0.02$ ). As a result of improved adherence, patients prescribed SPAA vs two-pill CCB plus statin therapy had significantly longer time to $\mathrm{CV}$ event (Figure 5). For comparison (3), when adherence was included as a covariate, the strength of association was reduced. The risk of $\mathrm{CV}$ events was significantly lower for adherent $\mathrm{CCB} /$ statin patients (HR: $0.79 ; P=0.01$ ) and adherent SPAA patients (HR: $0.61 ; P=0.03$ ) compared with patients nonadherent to two-pill therapy $(\mathrm{CCB} / \mathrm{statin}$ patients), suggesting differences in adherence may play a role in SPAA's observed benefit.

Some limitations to these real-world evaluations should be taken into account. All of these studies were conducted in the USA and the results may not be directly applicable to other geographical regions due to differences in clinical practice between healthcare systems or the prevalence of CV comorbidities in other parts of the world. Further studies are therefore warranted in other patient populations to determine the beneficial effect of SPAA on adherence and $\mathrm{CV}$ outcomes, reported in these retrospective US studies.

\section{Patient satisfaction/patient acceptability}

There is increasing evidence that patient satisfaction with therapy improves adherence ${ }^{88,89}$ and, conversely, that patient dissatisfaction leads to poor adherence. ${ }^{90}$ Therefore, medications that improve patient satisfaction may contribute towards improving health status, lowering healthcare use, shortening hospital stays, and improving continuity of care.

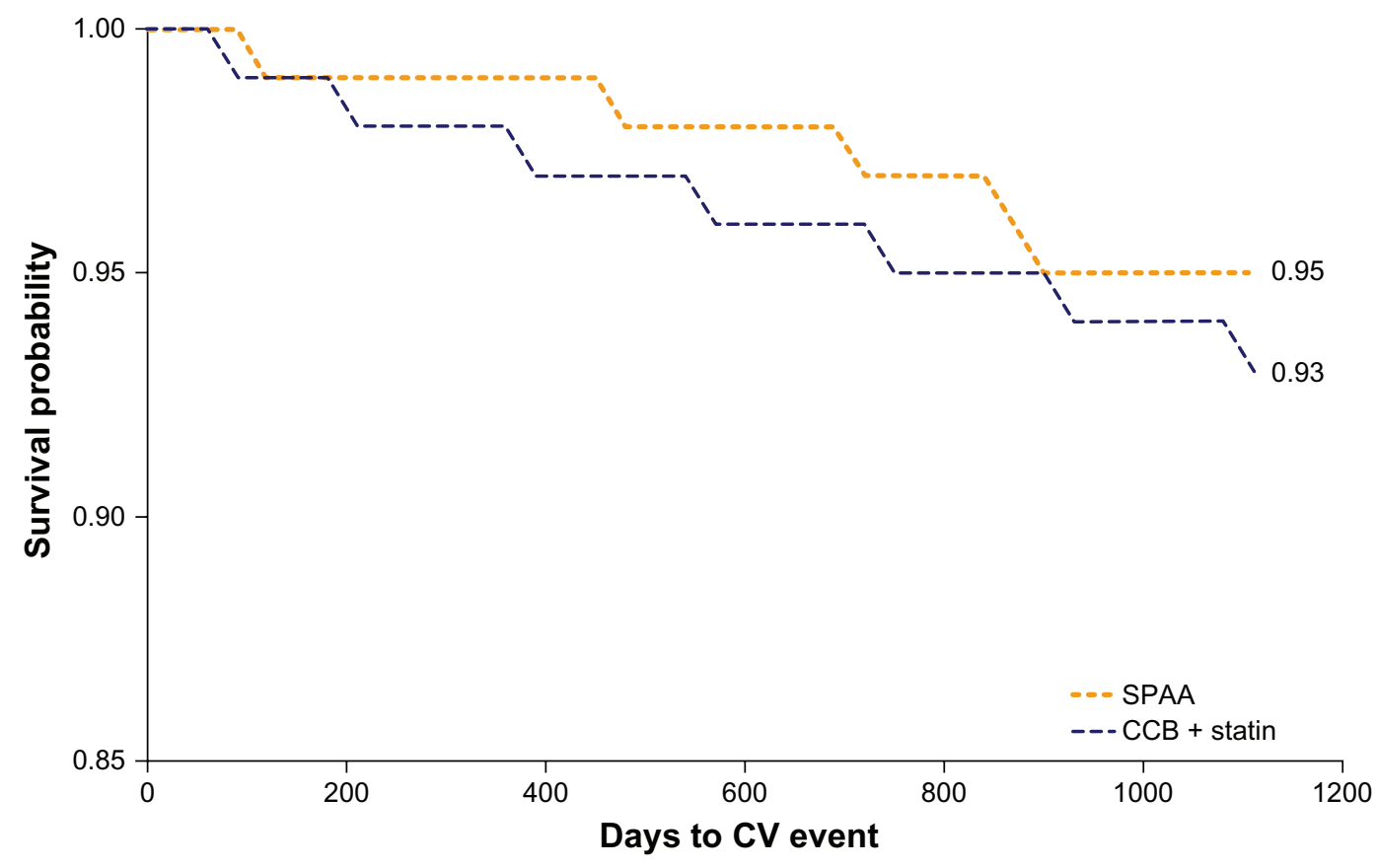

Figure 5 Kaplan-Meier analysis of days to CV event in patients receiving SPAA and co-administered CCB and statin. Abbreviations: CCB, calcium channel blocker; CV, cardiovascular; SPAA, single-pill amlodipine/atorvastatin. 
Patient satisfaction is therefore an important aspect of a patient's treatment regimen. Patient satisfaction with SPAA vs a multiple-pill regimen was investigated in some pilot studies. The Expectations and Satisfaction with Treatment Questionnaire (ESTQ) was developed through patient focus groups and clinician interviews as a tool to determine patients' expectations for, satisfaction with, and adherence to treatment for HTN and DYS. This questionnaire was originally tested during the AVALON study ${ }^{41}$ and later modified to the ESTQ short form (ESTQ-SF). ${ }^{46}$ Using data from the JEWEL program, ${ }^{46,56}$ SPAA treatment was shown to increase patient satisfaction vs a multiple-pill regimen. ${ }^{46}$ Due to the preliminary nature of these data, further study is needed before firm conclusions can be drawn on whether an increase in patient satisfaction with SPAA contributes to the improved adherence observed with SPAA vs multiple-pill regimens.

\section{Conclusion}

Much of the proposed benefits of the Polypill ${ }^{\mathrm{TM}}$ can be achieved through reducing BP and LDL-C. There is now a wealth of preclinical, clinical, and outcomes research data supporting the use of a combination of amlodipine and atorvastatin into a single-pill therapy. The recently completed CRUCIAL trial conducted in patients with HTN and three or more additional $\mathrm{CV}$ risk factors but no CHD demonstrated that a SPAA-based proactive intervention strategy can improve BP and LDL-C goal attainment and reduce calculated $\mathrm{CV}$ risk in comparison with UC alone. Taken together, these findings suggest that SPAA can play an important role in helping physicians improve the management of $\mathrm{CV}$ risk in their patients.

\section{Acknowledgments/Disclosure}

Editorial support was provided by Karen Burrows and Penny Gorringe of UBC Scientific Solutions and funded by Pfizer Inc. Professor Zamorano has served as a consultant or has received travel expenses, or payment for speaking at meetings, or funding for research from one or more pharmaceutical companies (including Pfizer, who manufacture single-pill amlodipine/atorvastatin) that market blood pressure-lowering or lipid-lowering drugs. Dr Edwards of UBC Scientific Solutions was a paid consultant to Pfizer Inc in connection with development of this paper.

\section{References}

1. Zanchetti A. The hypertensive patient with multiple risk factors: is treatment really so difficult? Am J Hypertens. 1997;10:223S-229S.

2. Gu D, Gupta A, Muntner P, et al. Prevalence of cardiovascular disease risk factor clustering among the adult population of China: results from the International Collaborative Study of Cardiovascular Disease in Asia (InterAsia). Circulation. 2005;112:658-665.
3. Asmar R, Vol S, Pannier B, Brisac AM, Tichet J, El Hasnaoui A. High blood pressure and associated cardiovascular risk factors in France. J Hypertens. 2001;19:1727-1732.

4. Kannel WB. Fifty years of Framingham Study contributions to understanding hypertension. J Hum Hypertens. 2000;14:83-90.

5. Neaton JD, Wentworth D. Serum cholesterol, blood pressure, cigarette smoking, and death from coronary heart disease. Overall findings and differences by age for 316,099 white men. Multiple Risk Factor Intervention Trial Research Group. Arch Intern Med. 1992;152: 56-64.

6. Thomas F, Bean K, Guize L, Quentzel S, Argyriadis P, Benetos A. Combined effects of systolic blood pressure and serum cholesterol on cardiovascular mortality in young $(<55$ years $)$ men and women. Eur Heart J. 2002;23:528-535.

7. Executive Summary of The Third Report of the National Cholesterol Education Program (NCEP) Expert Panel on Detection, Evaluation, and Treatment of High Blood Cholesterol in Adults (Adult Treatment Panel III). JAMA. 2001;285:2486-2497.

8. Chobanian AV, Bakris GL, Black HR, et al. The Seventh Report of the Joint National Committee on Prevention, Detection, Evaluation, and Treatment of High Blood Pressure: the JNC 7 report. JAMA. 2003;289:2560-2572.

9. Graham I, Atar D, Borch-Johnsen K, et al. European guidelines on cardiovascular disease prevention in clinical practice: executive summary: Fourth Joint Task Force of the European Society of Cardiology and Other Societies on Cardiovascular Disease Prevention in Clinical Practice (Constituted by representatives of nine societies and by invited experts). Eur Heart J. 2007;28:2375-2414.

10. Mancia G, De Backer G, Dominiczak A, et al. 2007 Guidelines for the Management of Arterial Hypertension: The Task Force for the Management of Arterial Hypertension of the European Society of Hypertension (ESH) and of the European Society of Cardiology (ESC). J Hypertens. 2007;25:1105-1187.

11. ALLHAT Officers and Coordinators for the ALLHAT Collaborative Research Group. Major outcomes in high-risk hypertensive patients randomized to angiotensin-converting enzyme inhibitor or calcium channel blocker vs diuretic: The Antihypertensive and Lipid-Lowering Treatment to Prevent Heart Attack Trial (ALLHAT). JAMA. 2002;288: 2981-2997.

12. Sever PS, Dahlöf B, Poulter NR, et al. Prevention of coronary and stroke events with atorvastatin in hypertensive patients who have average or lower-than-average cholesterol concentrations, in the Anglo-Scandinavian Cardiac Outcomes Trial-Lipid Lowering Arm (ASCOT-LLA): a multicentre randomised controlled trial. Lancet. 2003;361:1149-1158.

13. Wald NJ, Law MR. A strategy to reduce cardiovascular disease by more than $80 \%$. BMJ. 2003;326:1419.

14. Colhoun HM, Betteridge DJ, Durrington PN, et al. Primary prevention of cardiovascular disease with atorvastatin in type 2 diabetes in the Collaborative Atorvastatin Diabetes Study (CARDS): multicentre randomised placebo-controlled trial. Lancet. 2004;364: 685-696.

15. Gæde P, Vedel P, Larsen N, Jensen GV, Parving HH, Pedersen O. Multifactorial intervention and cardiovascular disease in patients with type 2 diabetes. N Engl J Med. 2003;348:383-393.

16. Gæde P, Lund-Andersen H, Parving HH, Pedersen O. Effect of a multifactorial intervention on mortality in type 2 diabetes. $N$ Engl J Med. 2008;358:580-591.

17. Yusuf S, Pais P, Afzal R, et al. Effects of a polypill (Polycap) on risk factors in middle-aged individuals without cardiovascular disease (TIPS): a phase II, double-blind, randomised trial. Lancet. 2009;373: 1341-1351.

18. Patel A, Shah T, Shah G, et al. Preservation of bioavailability of ingredients and lack of drug-drug interactions in a novel five-ingredient polypill (polycap): a five-arm phase I crossover trial in healthy volunteers. Am J Cardiovasc Drugs. 2010;10:95-103. 
19. Malekzadeh F, Marshall T, Pourshams A, et al. A pilot double-blind randomised placebo-controlled trial of the effects of fixed-dose combination therapy ('polypill') on cardiovascular risk factors. Int J Clin Pract. 2010;64:1220-1227.

20. Sleight P, Pouleur H, Zannad F. Benefits, challenges, and registerability of the polypill. Eur Heart J. 2006;27:1651-1656.

21. Zamorano J, Erdine S, Lopez AP, et al. Cardiovascular risk factor management - single-pill amlodipine/atorvastatin versus usual care in patients with hypertension and additional risk factors: the CRUCIAL trial. Curr Med Res Opin. 2011;27:821-833.

22. Blank R, Hobbs FD, Zamorano J, Girerd X. A single-pill combination of amlodipine besylate and atorvastatin calcium (update). Drugs Today (Barc). 2007;43:157-177.

23. McKeage K, Siddiqui MA. Amlodipine/atorvastatin fixed-dose combination: a review of its use in the prevention of cardiovascular disease and in the treatment of hypertension and dyslipidemia. Am J Cardiovasc Drugs. 2008;8:51-67.

24. Curran MP. Amlodipine/atorvastatin: a review of its use in the treatment of hypertension and dyslipidaemia and the prevention of cardiovascular disease. Drugs. 2010;70:191-213.

25. Whitworth JA. 2003 World Health Organization (WHO)/International Society of Hypertension (ISH) statement on management of hypertension. J Hypertens. 2003;21:1983-1992.

26. Kotseva K, Wood D, De Backer G, De Bacquer D, Pyörälä K, Keil U. EUROASPIRE III: a survey on the lifestyle, risk factors and use of cardioprotective drug therapies in coronary patients from 22 European countries. Eur J Cardiovasc Prev Rehabil. 2009;16:121-137.

27. Yokokawa H, Goto A, Sanada H, Watanabe T, Yasumura S. Longitudinal community-based assessment of blood pressure control among Japanese hypertensive patients: Fukushima research of hypertension (FRESH). J Clin Hypertens. 2010;12:166-173.

28. Julius S, Kjeldsen SE, Weber M, et al. Outcomes in hypertensive patients at high cardiovascular risk treated with regimens based on valsartan or amlodipine: the VALUE randomised trial. Lancet 2004;363:2022-2031.

29. Dahlöf B, Sever PS, Poulter NR, et al. Prevention of cardiovascular events with an antihypertensive regimen of amlodipine adding perindopril as required versus atenolol adding bendroflumethiazide as required, in the Anglo-Scandinavian Cardiac Outcomes Trial-Blood Pressure Lowering Arm (ASCOT-BPLA): a multicentre randomised controlled trial. Lancet. 2005;366:895-906.

30. Nissen SE, Tuzcu EM, Libby P, et al. Effect of antihypertensive agents on cardiovascular events in patients with coronary disease and normal blood pressure: the CAMELOT study: a randomized controlled trial. JAMA. 2004;292:2217-2225.

31. Bisognano J, McLaughlin T, Roberts CS, et al. Incremental effectiveness of amlodipine besylate in the treatment of hypertension with single and multiple medication regimens. Am J Hypertens. 2004;17:676-683.

32. Haria M, Wagstaff AJ. Amlodipine. A reappraisal of its pharmacological properties and therapeutic use in cardiovascular disease. Drugs. 1995;50:560-586.

33. LaRosa JC, Grundy SM, Waters DD, et al. Intensive lipid lowering with atorvastatin in patients with stable coronary disease. $N$ Engl J Med. 2005;352:1425-1435.

34. Malhotra HS, Goa KL. Atorvastatin: an updated review of its pharmacological properties and use in dyslipidaemia. Drugs. 2001;61: 1835-1881.

35. Pfizer Inc. Lipitor ${ }^{\circledR}$ (atorvastatin calcium) [package insert]. Pfizer Inc; New York. Available at: http://www.pfizer.com/files/products/uspi lipitor.pdf. Accessed February 24, 2011.

36. Pfizer Inc. Norvasc ${ }^{\circledR}$ (amlodipine besylate) [package insert]. Pfizer Inc; New York. Available at: http://media.pfizer.com/files/products/ uspi_norvasc.pdf. Accessed February 23, 2011.

37. Pfizer Inc. Caduet ${ }^{\mathbb{R}}$ (amlodipine besylate/atorvastatin calcium) [package insert]. Pfizer Inc; New York. Available at: http://labeling.pfizer.com/ ShowLabeling.aspx?id=531. Accessed February 24, 2011.
38. Blank R. A single-pill combination of amlodipine besylate and atorvastatin calcium. Drugs Today (Barc). 2006;42:157-175.

39. Chung M, Calcagni A, Glue P, Bramson C. Bioavailability of amlodipine besylate/atorvastatin calcium combination tablet. J Clin Pharmacol. 2006;46:1030-1037.

40. Chung M, Calcagni A, Glue P, Bramson C. Effect of food on the bioavailability of amlodipine besylate/atorvastatin calcium combination tablet. J Clin Pharmacol. 2006;46:1212-1216.

41. Messerli FH, Bakris GL, Ferrera D, et al. Efficacy and safety of coadministered amlodipine and atorvastatin in patients with hypertension and dyslipidemia: results of the AVALON trial. J Clin Hypertens. 2006;8:571-581.

42. Preston RA, Harvey $\mathrm{P}$, Herfert $\mathrm{O}$, et al. A randomized, placebocontrolled trial to evaluate the efficacy, safety, and pharmacodynamic interaction of coadministered amlodipine and atorvastatin in 1660 patients with concomitant hypertension and dyslipidemia: the Respond trial. J Clin Pharmacol. 2007;47:1555-1569.

43. Sever PS, Dahlöf B, Poulter NR, et al. Potential synergy between lipid-lowering and blood-pressure-lowering in the AngloScandinavian Cardiac Outcomes Trial. Eur Heart J. 2006;27: 2982-2988.

44. Mason RP, Kubant R, Heeba G, et al. Synergistic effect of amlodipine and atorvastatin in reversing LDL-induced endothelial dysfunction. Pharm Res. 2008;25:1798-1806.

45. Cohn JN, Wilson DJ, Neutel J, et al. Coadministered amlodipine and atorvastatin produces early improvements in arterial wall compliance in hypertensive patients with dyslipidemia. Am J Hypertens. $2009 ; 22: 137-144$.

46. Merikle EP, Evans C, Feldman RD. Patient satisfaction with a single-pill treatment of hypertension and dyslipidemia. Circulation. 2007;115:e589 [Abstract].

47. Packer M, O'Connor CM, Ghali JK, et al. Effect of amlodipine on morbidity and mortality in severe chronic heart failure. Prospective Randomized Amlodipine Survival Evaluation Study Group. $N$ Engl J Med. 1996;335:1107-1114.

48. LaRosa JC, Grundy SM, Kastelein JJ, Kostis JB, Greten H. Safety and efficacy of atorvastatin-induced very low-density lipoprotein cholesterol levels in patients with coronary heart disease (a post hoc analysis of the Treating to New Targets [TNT] study). Am J Cardiol. 2007;100:747-752.

49. Newman C, Tsai J, Szarek M, Luo D, Gibson E. Comparative safety of atorvastatin $80 \mathrm{mg}$ versus $10 \mathrm{mg}$ derived from analysis of 49 completed trials in 14,236 patients. Am J Cardiol. 2006;97: 61-67.

50. Amarenco P, Bogousslavsky J, Callahan A 3rd, et al. High-dose atorvastatin after stroke or transient ischemic attack. $N$ Engl J Med. 2006;355:549-559.

51. Blank R, Lasalle J, Reeves R, Maroni J, Tarasenko L, Sun F. Single-pill therapy in the treatment of concomitant hypertension and dyslipidemia (the Amlodipine/Atorvastatin Gemini Study). J Clin Hypertens (Greenwich). 2005;7:264-273.

52. Erdine S, Ro YM, Tse HF, et al. Single-pill amlodipine/atorvastatin helps patients of diverse ethnicity attain recommended goals for blood pressure and lipids (the Gemini-AALA study). J Hum Hypertens. 2009;23:196-210.

53. Hobbs FD, Gensini G, Mancini GB, et al. Can combining different risk interventions into a single formulation contribute to improved cardiovascular disease risk reduction? Rationale and design for an international, open-label program to assess the effectiveness of a single pill (amlodipine/atorvastatin) to attain recommended target levels for blood pressure and lipids (The JEWEL Program). Int J Cardiol. 2006;110:242-250.

54. Flack JM, Victor R, Watson K, et al. Improved attainment of blood pressure and cholesterol goals using single-pill amlodipine/atorvastatin in African Americans: the CAPABLE trial. Mayo Clin Proc. 2008;83:35-45 
55. Ferdinand KC, Flack JM, Saunders E, et al. Amlodipine/atorvastatin single-pill therapy for blood pressure and lipid goals in African Americans: influence of the metabolic syndrome and type 2 diabetes mellitus. J Clin Hypertens (Greenwich). 2009;11:585-593.

56. Hobbs FDR, Gensini G, Mancini GBJ, et al. International open-label studies to assess the efficacy and safety of single-pill amlodipine/ atorvastatin in attaining blood pressure and lipid targets recommended by country-specific guidelines: the JEWEL programme. Eur $J$ Cardiovasc Prev Rehabil. 2009;16:472-480.

57. Flack JM, Feldman RD, Hobbs FDR, et al. Reduction in blood pressure and low-density lipoprotein cholesterol when single-pill amlodipine/ atorvastatin is used as a first line or add-on treatment. Presented at the 2nd International Conference on Fixed Combination in the Treatment of Hypertension and Dyslipidemia, 2009; Valencia, Spain.

58. Feldman RD, Flack JM, Hobbs FDR, et al. A comparison of blood pressure and low-density lipoprotein cholesterol reduction after treatment with single-pill amlodipine/atorvastatin in elderly ( $>75$ years) and younger ( $<75$ years) patients: results of a pooled analysis of 5559 patients. Presented at The 2nd International Conference on Fixed Combination in the Treatment of Hypertension and Dyslipidemia; 2009, Valencia, Spain.

59. Hobbs R, Feldman R, Flack J, et al. A comparison of blood pressure and low-density lipoprotein cholesterol reduction after treatment with single-pill amlodipine/atorvastatin in younger $(<65$ years $)$ and older ( $\geq 65$ years) men and women: Results of a pooled analysis of 5559 patients. Presented at The 2nd International Conference on Fixed Combination in the Treatment of Hypertension and Dyslipidemia, 2009; Valencia, Spain 2009.

60. Neutel JM, Bestermann WH, Dyess EM, et al. The use of a single-pill calcium channel blocker/statin combination in the management of hypertension and dyslipidemia: a randomized, placebo-controlled, multicenter study. J Clin Hypertens (Greenwich). 2009;11:22-30.

61. Grimm R, Malik M, Yunis C, Sutradhar S, Kursun A. Simultaneous treatment to attain blood pressure and lipid goals and reduced CV risk burden using amlodipine/atorvastatin single-pill therapy in treated hypertensive participants in a randomized controlled trial. Vasc Health Risk Manag. 2010;6:261-271.

62. Wilson PW, D'Agostino RB, Levy D, Belanger AM, Silbershatz H, Kannel WB. Prediction of coronary heart disease using risk factor categories. Circulation. 1998;97:1837-1847.

63. Conroy RM, Pyörälä K, Fitzgerald AP, et al. Estimation of ten-year risk of fatal cardiovascular disease in Europe: the SCORE project. Eur Heart J. 2003;24:987-1003.

64. D'Agostino RB Sr, Vasan RS, Pencina MJ, et al. General cardiovascular risk profile for use in primary care. The Framingham Heart Study. Circulation. 2008;117:743-753.

65. Wolf PA, D'Agostino RB, Belanger AJ, Kannel WB. Probability of stroke: a risk profile from the Framingham Study. Stroke. 1991;22:312-318.

66. Zamorano J, Erdine S, Lopez Pavia A, et al. Single-pill amlodipine/ atorvastatin versus usual care for cardiovascular risk factor management in patients with diabetes, hypertension and additional risk factors a CRUCIAL trial subanalysis. 2010; Presented at the 23rd International Society of Hypertension; 2010, Vancouver, BC.

67. Zamorano J, Erdine S, Lopez Pavia A, et al. Single-pill amlodipine/ atorvastatin versus usual care for cardiovascular risk factor management in patients aged 65 years or more with hypertension and additional risk factors-a CRUCIAL trial subanalysis 2010; Presented at the 23rd International Society of Hypertension, 2010; Vancouver, BC.

68. Cho EJ, Kim JH, Sutradhar S, et al. Reduction in cardiovascular risk using proactive multifactorial intervention is consistent regardless of ethnicity in Asian patients: Sub-analysis of the CRUCIAL Trial. The 43rd Annual Scientific Meeting of the Japan Atherosclerosis Society, 2011; Sapporo, Japan.

69. Risk assessment chart for death from cardiovascular disease based on a 19-year follow-up study of a Japanese representative population. Circ J. 2006;70:1249-1255.
70. Kim JH, Cho EJ, Sutradhar S, et al. Cardiovascular risk reduction in Pacific-Asian patients using a multifactorial intervention as assessed by using the NIPPON DATA80, SCORE and Framingham equations: CRUCIAL Trial sub-analysis. The 43rd Annual Scientific Meeting of the Japan Atherosclerosis Society, 2011; Sapporo, Japan.

71. Lindgren P, Buxton M, Kahan T, et al. The lifetime cost-effectiveness of amlodipine-based therapy + atorvastatin compared to atenolol + atorvastatin, amlodipine-based therapy alone and atenolol-based therapy alone: Results from the Anglo-Scandinavian Cardiac Outcomes Trial (ASCOT). Pharmacoeconomics. 2009;27:221-230.

72. Bangalore S, Kamalakkannan G, Parkar S, Messerli FH. Fixed-dose combinations improve medication compliance: a meta-analysis. $\mathrm{Am} \mathrm{J}$ Med. 2007;120:713-719.

73. Ho PM, Bryson CL, Rumsfeld JS. Medication adherence: its importance in cardiovascular outcomes. Circulation. 2009;119: 3028-3035.

74. Chapman RH, Yeaw J, Roberts CS. Association between adherence to calcium-channel blocker and statin medications and likelihood of cardiovascular events among US managed care enrollees. $B M C$ Cardiovasc Disord. 2010;10:29.

75. Ho PM, Magid DJ, Shetterly SM, et al. Medication nonadherence is associated with a broad range of adverse outcomes in patients with coronary artery disease. Am Heart J. 2008;155:772-779.

76. Ho PM, Spertus JA, Masoudi FA, et al. Impact of medication therapy discontinuation on mortality after myocardial infarction. Arch Intern Med. 2006;166:1842-1847.

77. Ho PM, Magid DJ, Shetterly SM, et al. Importance of therapy intensification and medication nonadherence for blood pressure control in patients with coronary disease. Arch Intern Med. 2008;168: 271-276.

78. Cherry SB, Benner JS, Hussein MA, Tang SSK, Nichol MB. The clinical and economic burden of nonadherence with antihypertensive and lipid-lowering therapy in hypertensive patients. Value Health. 2009;12:489-497.

79. Lindgren P, Eriksson J, Buxton M, et al. The economic consequences of non-adherence to lipid-lowering therapy: results from the Anglo-Scandinavian-Cardiac Outcomes Trial. Int J Clin Pract. 2010 64:1228-1234.

80. Chapman RH, Benner JS, Petrilla AA, et al. Predictors of adherence with antihypertensive and lipid-lowering therapy. Arch Intern Med. 2005; $165: 1147-1152$.

81. Benner JS, Chapman RH, Petrilla AA, Tang SSK, Rosenberg N, Schwartz JS. Association between prescription burden and medication adherence in patients initiating antihypertensive and lipid-lowering therapy. Am J Health Syst Pharm. 2009;66:1471-1477.

82. Agarwal S, Tang SSK, Rosenberg N, et al. Does synchronizing initiation of therapy affect adherence to concomitant use of antihypertensive and lipid-lowering therapy? Am J Ther. 2009;16:119-126.

83. Petrilla AA, Benner JS, Battleman DS, Tierce JC, Hazard EH. Evidence-based interventions to improve patient compliance with antihypertensive and lipid-lowering medications. Int $J$ Clin Pract. 2005; 59:1441-1451.

84. Chapman RH, Ferrufino CP, Kowal SL, Classi P, Roberts CS. The cost and effectiveness of adherence-improving interventions for antihypertensive and lipid-lowering drugs. Int J Clin Pract. 2010;64: 169-181.

85. Patel BV, Leslie RS, Thiebaud P, et al. Adherence with single-pill amlodipine/atorvastatin vs a two-pill regimen. Vasc Health Risk Manag. 2008;4:673-681.

86. Hussein MA, Chapman RH, Benner JS, et al. Does a single-pill antihypertensive/lipid-lowering regimen improve adherence in US managed care enrolees? A non-randomized, observational, retrospective study. Am J Cardiovasc Drugs. 2010;10:193-202.

87. Chapman RH, Pelletier EM, Smith PJ, Roberts CS. Can adherence to antihypertensive therapy be used to promote adherence to statin therapy? Patient Prefer Adherence. 2009;3:265-275. 
88. Roberts KJ. Physician-patient relationships, patient satisfaction, and antiretroviral medication adherence among HIV-infected adults attending a public health clinic. AIDS Patient Care STDS. 2002;16: 43-50.

89. Wroth TH, Pathman DE. Primary medication adherence in a rural population: the role of the patient-physician relationship and satisfaction with care. J Am Board Fam Med. 2006;19:478-486.
90. Renzi C, Picardi A, Abeni D, et al. Association of dissatisfaction with care and psychiatric morbidity with poor treatment compliance. Arch Dermatol. 2002;138:337-342.

Integrated Blood Pressure Control

\section{Publish your work in this journal}

Integrated Blood Pressure Control is an international, peer-reviewed open-access journal focusing on the integrated approach to managing hypertension and risk reduction. Treating the patient and comorbidities together with diet and lifestyle modification and optimizing healthcare resources through a multidisciplinary team approach constitute key features of the journal. This journal is indexed on American Chemical Society's Chemical Abstracts Service (CAS). The manuscript management system is completely online and includes a very quick and fair peerreview system, which is all easy to use. Visit http://www.dovepress.com/ testimonials.php to read real quotes from published authors.

\footnotetext{
Submit your manuscript here: http://www.dovepress.com/integrated-blood-pressure-control-journal
} 